\title{
Procurement and commissioning during COVID-19: reflections and (early) lessons
}

\author{
Albert SanChez-Graells* \\ University of Bristol
}

\begin{abstract}
This commentary reflects on some common themes that are starting to emerge in the early analysis of the healthcare procurement and commissioning response to the COVID-19 pandemic. Although it largely results from the observation of the situation in the English NHS, the most salient issues are common to procurement in other EU bealthcare systems, as well as more broadly across areas of the public sector that have strongly relied on the extremely urgent procurement exception in the aftermath of the first wave of the pandemic. Given the disfunction and abuse of 'unregulated procurement' in the context of COVID-19, the commentary reflects on the longer term need for suitable procurement rules to face impending challenges, such as Brexit and, more importantly, climate change.
\end{abstract}

Keywords: procurement; commissioning; healthcare; COVID-19; pandemic; extreme urgency; unregulated procurement; probity; integrity; conflicts of interest.

\section{Introduction}

A few months after the start of the COVID-19 pandemic, the impact of the extreme A public health emergency on public governance mechanisms is still being acutely felt, both internationally and domestically. The long-term implications of this crisis are yet to take shape, ${ }^{1}$ but there are already some indications of potentially significant developments

* Professor of Economic Law and Member of the Centre for Health, Law, and Society at the University of Bristol Law School. This commentary results from active discussions in a webinar of the same title held at the University of Bristol Law School on 30 September 2020. I am indebted to the speakers and participants for very thought-provoking exchanges. A previous version of this commentary, including links to the presentations given by the speakers, was published in the University of Bristol Law School Research Blog on 5 October $2020<$ https://legalresearch.blogs.bris.ac.uk/2020/10/healthcare-procurement-andcommissioning-during-covid-19-reflections-and-early-lessons-some-thoughts-after-a-very-interestingwebinar/>. Commentswelcome: a.sanchez-graells@bristol.ac.uk.

1 For high-level reflection, see REFORM, 'Building a resilient state: a collection of essays' (October 2020) $<$ https:/reform.uk/research/building-resilient-state-collection-essays $>$. 
at EU level, ${ }^{2}$ as well as evidence of the heightened risks for the UK's public health system post-Brexit. ${ }^{3}$

Healthcare procurement and commissioning have been at the very forefront of the initial reaction to the COVID-19 pandemic. $^{4}$ As discussed in an earlier contribution to this journal, where unforeseeable and extremely urgent circumstances not attributable to the contracting authority arise, public procurement rules get out of the way to free public buyers up to do all they can to get the required supplies and equipment. ${ }^{5}$ The last few months have thus been, to put it simply, the longest period of (largely) unregulated procurement on record - and definitely the largest period since the inception of the EU public procurement rules.

The scattered evidence that continuously appears through the media, ${ }^{6}$ as well as the more systematic reports that are starting to emerge, ${ }^{7}$ show some evidence of positive adaptations to the immense challenges, ${ }^{8}$ but also a clear disfunction of the (deactivated) mechanisms to ensure probity and integrity in procurement, and potential for abuse of extremely urgent 'unregulated procurement'.

Against this background, on 30 September 2020, the Centre for Health, Law, and Society of the University of Bristol Law School had the honour of hosting an excellent panel of speakers for a webinar on 'Healthcare procurement and commissioning during COVID-19: reflections and (early) lessons'. The speakers provided short presentations on a host of very complementary issues surrounding the reaction of NHS procurement and commissioning to the COVID-19 challenges. The ensuing discussion brought to light a number of general themes that are, by and large, aligned with the worries that others and

2 For discussion, see S Greer and A de Ruijter, 'EU health law and policy in and after the COVID-19 crisis' (2020) 30(4) European Journal of Public Health 623-624; T Clemens and H Brand, 'Will COVID-19 lead to a major change of the EU public health mandate? A renewed approach to EU's role is needed' (2020) 30(4) European Journal of Public Health 624-625; M Guy, 'Towards a European health union: what role for member states?' (2020) Journal of Risk Regulation, advanced access <https://doi.org/10.1017/err.2020.77>

3 See e.g. N Fahy, T Hervey, M Dayan et al, 'Assessing the potential impact on health of the UK's future relationship agreement with the EU: analysis of the negotiating positions' (2020) Health Economics, Policy and Law, advanced access < https://doi.org/10.1017/S1744133120000171>.

4 See e.g. Organisation for Economic Co-operation and Development, 'Stocktaking report on immediate public procurement and infrastructure responses to COVID-19' (updated 24 June 2020)

$<$ www.oecd.org/coronavirus/policy-responses/stocktaking-report-on-immediate-public-procurement-andinfrastructure-responses-to-covid-19-248d0646/>.

5 A Sanchez-Graells, 'Procurement in the time of COVID-19' (2020) 71(1) Northern Ireland Legal Quarterly 81-87.

6 For an early overview, see A Sanchez-Graells, "1 Billion problems in using extremely urgent public procurement to evade accountability?’ (howtocrackanut.com, 17 May 2020)

$<$ www.howtocrackanut.com/blog/2020/5/18/1-billion-problems-in-using-extremely-urgent-publicprocurement-to-evade-accountability>.

7 See e.g. House of Commons Public Accounts Committee, 'Whole of government response to COVID-19', Thirteenth Report of Session 2019-2021 (23 July 2020) paras 15-17

<https://publications.parliament.uk/pa/cm5801/cmselect/cmpubacc/404/40402.htm>; or National Audit Office, 'Investigation into how government increased the number of ventilators available to the NHS in response to COVID-19' (30 September 2020) <www.nao.org.uk/report/increasing-ventilator-capacity-inresponse-to-covid-19/>. However, the more relevant reports are still work-in-progress. See e.g. National Audit Office, 'Supplying the NHS and adult social care sector with personal protective equipment (PPE)' $<$ www.nao.org.uk/work-in-progress/supplying-the-nhs-and-adult-social-care-sector-with-personalprotective-equipment-ppe/>; and National Audit Office, 'Government procurement during the COVID-19 pandemic' < www.nao.org.uk/work-in-progress/government-procurement-during-the-covid-19-pandemic/>.

8 Confederation of British Industry, 'Public-private partnerships: lessons from COVID-19’ (September 2020) $<$ www.cbi.org.uk/media/5623/public-private-partnership-lessons-from-covid-19.pdf>. 
I had expressed at the outset of the pandemic, and a number of challenges that will shape the readjustment or reregulation of procurement and commissioning in the medium and long term.

The remainder of this commentary initially provides some brief notes on the most salient points made by the speakers in their presentations, which do not aim to be exhaustive. It then goes on to offer my own reflections and views on what lessons can be extracted from the procurement and commissioning reaction to the first wave of COVID-19, which do not necessarily represent those of the panel of speakers.

\section{Presentations by the panel ${ }^{9}$}

Ms Neli Garbuzanova, Senior Procurement Manager (NHS) and Member of the European Commission Stakeholder Expert Group on Public Procurement, provided an 'Overview of the impact of COVID-19 on NHS procurement and commissioning'. Neli used a cycle-based analytical model of NHS procurement and commissioning, 10 highlighting the need for adjustments to the model in times of crisis but within certain limits. She presented the impact of COVID-19 at different stages of this cycle and stressed the various practical and governance challenges raised by the pandemic, as well as the main adaptations implemented during the first wave. Reflecting on potential governance shortcomings, Neli stressed the difficulties in enforcing rules on conflict of interest, as well as some of the new guidance on payment. She acknowledged the heterogeneous nature of pandemic 'needs', calling for a more targeted approach to commissioning and procurement with the lapse of time and increase of knowledge about the disease. Neli also offered interesting insights into future challenges derived from extreme urgency awards, including the need to modify 'rushed' contracts as the specific needs of a (potential) second wave become better understood. She also stressed the necessity for stronger collaboration at all levels, especially in times of crisis, which could build on some NHS national and local best practices.

Mr Rob Knott, Commercial Director, Digital (Guy's and St Thomas' NHS Foundation Trust) and former National Director of NHS Procurement, provided a very practical view of 'Procuring in times of COVID-19. Challenges at the frontline'. Rob provided an insiders' view on the tensions between centralised procurement and local pressures to ensure safety and continuity in frontline delivery of NHS services, as well as broader reflections on the challenges faced by the sudden and extreme change of circumstances that the pandemic brought. He made it clear that (further) digitalisation is very much needed in order to gain a better (almost) real-time view of operational needs and supply chain capacity to address them. He also emphasised how the pandemic stressed ongoing challenges in ensuring a proper functioning of centralised NHS procurement, and a more collaborative and integrated NHS provision. From a broader perspective, he also stressed that there will be an immediate need to pay more attention to issues such as embedding

9 The speakers' slides are available via the earlier blog post at the University of Bristol Law School Blog <https://legalresearch.blogs.bris.ac.uk/2020/10/healthcare-procurement-and-commissioning-during-covid19-reflections-and-early-lessons-some-thoughts-after-a-very-interesting-webinar/ $>$.

10 See N Garbuzanova, 'A dynamic whole-cycle approach to public procurement: a practitioner's perspective on best-practice methodologies' (2019) 6(2) African Public Procurement Law Journal 88-133. This is coupled with a companion website: <www.procurementart.com>. 
social value ${ }^{11}$ and emerging new approaches to procurement to support longer-term economic goals post-COVID.

Dr Pedro Telles, Associate Professor, Law Department, Copenhagen Business School, discussed the 'Scope and limits to the use of the negotiated procedure for extreme urgency grounds', building on the views he had previously published in his personal blog. ${ }^{12}$ Pedro stressed that the reaction to the pandemic has evidenced the scope for potential abuse of the direct award of contracts on the basis of the 'extreme urgency' exemption, not only or primarily in healthcare, but across very significant areas of public sector activity. He reflected on the governance problems that arise if contracting authorities take a bullish approach to relying on this exemption from the procurement rules, as the ordinary checks and balances are unable to facilitate timely remedies in case of abuse. He went back to the basics of the EU and UK regulation of extremely urgent procurement and stressed the need for robust justifications of the proportionality and necessity of the 'unregulated' procurement, as well as for the lack of imputability of the circumstances generating the extremely urgent need to the contracting authority. He stressed in particular the need for cumulative analysis of all requirements.

Dr Kirsi-Maria Halonen, Adjunct Professor, Faculty of Law, University of Lapland, and Member of the European Commission Stakeholder Expert Group on Public Procurement, presented her reflections on the 'Governance challenges in extremely urgent procurement: do we need new rules?'. She provided further evidence of the scope for abuse of direct awards of contracts (in particular for personal protective equipment (PPE)) exempted on the basis of extremely urgent need. Kirsi pointed at some rather extreme cases emerging from the Nordic experience, which have even required the application of criminal statutes. This triggered her reflection on whether the current approach is adequate, as far as the existence of extreme urgency is largely understood to justify the complete setting aside of all integrity and accountability requirements. Her answer was a resounding 'no', which led her to advocate for a new minimum regulation of extremely urgent procurement that sought to preserve the application of crucial elements of the existing procurement framework, such as the application of mandatory exclusion grounds, a tighter control and neutralisation of potential conflicts of interest and the introduction of additional guarantees, for instance, where there are any advanced payments.

Dr Mary Guy, Lecturer in Law, Lancaster University Law School, and Founder of the Health in Europe - Virtual Discussion Forum, built on her insightful 2019 modelling of the interaction between the NHS and private providers of healthcare in England, ${ }^{13}$ to reflect on the 'Changing patterns of patient choice under COVID-19. What longer term implications?'. Mary explained how the immediate reaction to the pandemic significantly disrupted the different channels for the provision of both NHS and private healthcare, in particular as a result of two collective agreements aimed to bring private capacity under the NHS umbrella to both support the management of the crisis and to facilitate continuity in the provision of key services. Mary also reflected on the underpinning exclusion orders, which disapply competition law in the healthcare sector for the purposes

11 See Procurement Policy Note on Taking Account of Social Value in the Award of Central Government Contracts (PPN 06/20, September 2020)

<https://assets.publishing.service.gov.uk/government/uploads/system/uploads/attachment_data/file/9214

37/PPN-06_20-Taking-Account-of-Social-Value-in-the-Award-of-Central-Government-Contracts.pdf > .

$12<$ www.telles.eu/>.

13 M Guy, "Between "going private" and "NHS privatisation": patient choice, competition reforms and the relationship between the NHS and private healthcare in England' (2019) 39(3) Legal Studies 479-498. 
of supporting that crisis and continuity-oriented collaboration between the NHS and private healthcare providers. She drew some interesting comparisons with similar approaches in other economic sectors (e.g. food retail distribution, ${ }^{14}$ but also more generally ${ }^{15}$ ) and reflected on whether the situation in the healthcare sector is different and, as such, will perhaps lead to a longer-lasting differentiated treatment, raising questions about the long-standing relationship between the NHS and private healthcare.

\section{Some reflections on common themes}

There are a few common themes in the discussions surrounding the procurement and commissioning challenges that the COVID-19 pandemic brought. Some of these are hardly new issues, but the pervasiveness of the pandemic and the extreme economic burden of the procurement associated with it have perhaps brought a new sense of urgency in trying to find solutions (if there are any, or any practicable ones) to the integrity and efficiency challenges that extremely urgent procurement generates.

\subsection{THE LIMITS OF 'EXTREME URGENCY'}

This is perhaps the obvious starting point. Extreme urgency is a sort of 'get away card' that sets aside procurement rules to free up public buyers to go to the market and get what is needed, when it is needed, (almost) no matter how. ${ }^{16}$ There are important questions here, such as whether this is indeed the adequate approach, how long can this exemption apply for, or whether the exemption from 'standard' procurement rules should not imply the possibility of 'unregulated procurement', but rather the triggering of a lighter-touch regime that solely concentrated on key elements of probity and good commercial processes and practice. Ultimately, extremely urgent procurement and commissioning are still procurement and commissioning, in the sense that they have to be conducted through some process and by reference to some commercial practices. Therefore, there is no absence of regulation, but perhaps only informal regulation in that context. ${ }^{17}$ The extent to which that should be formalised and constitute a special procurement regime will continue to trigger reflection and controversy. Equally, there are challenges in establishing the cut-off point at which the exemption can no longer apply because either the needs that are being satisfied through the relevant direct awards are no longer extremely urgent (e.g. in relation to foreseeable but not immediate needs), or because the continued extreme urgency is attributable to a lack of institutional reaction to the situation (e.g. in terms of dedicating additional resources, or prioritising some activities over others).

\subsection{IS THE HEALTHCARE SECTOR (PROCUREMENT) SPECIAL?}

This is another point of contention, as in particular it seems more difficult to insist on compliance with formal rules for healthcare-related procurement and commissioning when public health goals - i.e. lives - are directly at stake than, for example, in relation to the award of consultancy contracts of dubious direct relevance to the official messaging

14 On which see O Odudu, 'Feeding the nation in times of crisis: The relaxation of competition law in the United Kingdom' (2020) 19(2) Competition Law Journal 68-78.

15 O Odudu, 'UK \& COVID-19: an overview of the competition policy and leading cases' (24 September 2020) e-Competitions, Article No 96054 <www.concurrences.com/en/bulletin/special-issues/uk-covid19/uk-covid-19-an-overview-of-the-competition-policy-and-leading-cases-en>.

16 For more details, see Sanchez-Graells (n 6).

17 To avoid opening a can of worms on the concept of regulation, perhaps it is best to make a distinction between (binding) legal rules and other forms of regulation, such as guidance or practice. However, this issue exceeds the scope of this comment. 
about social-distancing measures. Rather than the need for a particularly lenient approach in the healthcare context, which can result in the unjustified syphoning-off of large amounts of public resources to the wrong providers or the acquisition of useless kit, it is perhaps better to think about it in terms of justification for the exemption. There is a sense that the excuse of the pandemic has been abused in some corners to simply engage in cronyism, if not worse. So, the issue is not so much whether something concerns a need for the direct provision of healthcare services, but whether there is a sufficiently close link between the intended provision of services and relevant public health goals. It is also worth stressing, as clearly emerged from the discussions in the webinar, that proper procurement has public health value or, seen from the other end, that bad procurement generates negative public health outcomes (e.g. every time supplies need to be discarded due to not being fit for purpose, with the ensuing operational risks and economic waste).

\subsection{IF NOT PROCUREMENT RULES, THEN WHAT?}

Another common theme concerns the possibility of keeping a wide procurement exemption as is (or, rather, as wide as it can be) and rely on other regulatory tools instead - such as other public law controls on the expenditure of public funds and, where adequate, criminal law. To my mind, the alternative this seems to present is a false one. Under their 'normal operation', procurement rules do not deactivate the rest of public and criminal law rules, but rather seek to diminish the need to rely on them. What this usually creates is a certain atrophy of those mechanisms, as the proper running of the procurement system tends to minimise the cases needing those types of interventions and as those mechanisms can be captured by political interests and manipulate the system for purposes other than ensuring the probity of public expenditure. This is exacerbated by the increasing reliance on the (judicialised) private enforcement of procurement rules, both as a mechanism to provide individual remedies and to uphold public interests, which seems to marginalise public oversight mechanisms to the uglier and uglier field of political football. From this perspective, it seems clear that taking all procurement rules out of the equation in the context of a major crisis can only put excessive pressure on a weakened set of accountability and responsibility mechanisms. This is not to say procurement rules should not be made more flexible in the face of extremely urgent needs, but rather to say that pinning all hopes of a proper and efficient expenditure of public funds on those other mechanisms may be wishful thinking. Once again, it seems that what is needed is more resource, including more resource for public oversight of compliance with the procurement and other rules in normal times, as well as in exceptional times.

\subsection{THE IMPORTANCE (AND PURPOSE) OF THE DIGITAL TRANSFORMATION}

Another common theme in the discussions is that digital technologies can make a very important contribution to streamlining access to information and to facilitating an earlier intervention, in particular in supply-chain management and to adjust imbalances related to frontline operational needs. This concerns for example the need to have better and more readily accessible information about existing suppliers and about companies that seek to contract with the public sector for the first time in the context of an emergency - which will ring many a bell for those advocating for the creation of (centralised or interconnected) procurement registers - as well as a more granular and real-time view of stockpiles, goods in transit, and effective use of, for example, consumables. I find the thrust of this discussion very important because the main claim is not that the digital transformation should seek to replace current operational or decision-making mechanisms (although some tasks could clearly be automated), but rather seek to support 
decision-makers and those at the frontline by giving them relevant, accurate and timely information on which to base their decisions. Similarly, the digital transformation should not seek to enforce rigid (algorithmic) determinations of supplier responsiveness, for instance, but rather empower contracting authorities to better assess their risks and, where appropriate, to take corrective or palliative measures (such as e.g. economic guarantees). All of this leads me to think that the digital transformation is in reality one new wave of information-based transformation and that, put in this light, it presents different opportunities and challenges than if thought of as the 'robofication' or 'AIfication' of procurement and, for example, healthcare services provision.

\subsection{AN OPPORTUNITY TO GET RID OF SYSTEMIC REGULATORY ANOMALIES?}

Another common theme is that the reaction to the pandemic could serve as a catalyst to correct systemic regulatory anomalies - e.g. the existence of convoluted 'standard' procurement rules that the 'unregulated COVID-19 procurement experience' could show as redundant or ineffective. ${ }^{18} \mathrm{I}$ am sceptical about the possibility of implementing significant changes, for instance, in the regulation of healthcare procurement, but also more generally. The reasons for this are difficult to articulate concisely, but suffice it to say that the pandemic is not precisely backing up the claim that unregulated procurement is superior to ordinary procurement in all cases and, as repeatedly stressed, the general approach to procurement regulation seeks to prevent bad procurement, rather than enable good procurement. While good procurement needs to be possible within the existing regulatory framework (and I think it is, as long as the flexibility of the system is properly understood and used), it seems clear that unregulated procurement simply generates the very risks that can undermine a proper functioning of the procurement function. Therefore, I think that it would be wrong to class procurement rules (or some/most of them) as an anomaly that gets in the way of commercial approaches by the public sector, in order to advocate for a much 'freer' procurement regime post-COVID. As others have argued, ${ }^{19}$ and very much in line with what Kirsi-Maria Halonen advocated in the webinar, the lessons seem to go very much in the opposite direction and to take us back to basics.

\section{Looking (not that far) into the future}

Beyond the discussions in the context of the pandemic, some of the issues and central themes also relate to some challenges that lurk in the (not-too-distant) future. I am particularly worried about the following two.

\subsection{ARE THERE MANY NEW LESSONS TO BE LEARNED? HOW HARD SHOULD WE TRY TO IDENTIFY THEM?}

One of the issues that will require a difficult decision is the extent to which the current massive wave of extremely urgent procurement should be subjected to post mortem analysis and to what purpose - especially as effective remedies will be nigh impossible to obtain and political responsibility does not seem to be the currency of the times. This concerns both public/political scrutiny and academic scrutiny. As a point of principle, no stone

18 The same is said of e.g. Brexit, as there is a clear appetite to rid (UK) procurers of the existing controls on their exercise of commercial discretion; see e.g. S Arrowsmith, 'Reimagining public procurement law after brexit: seven core principles for reform and their practical implementation' Part I (http://ssrn.com/abstract=3523172) and Part II (http://ssrn.com/abstract=3672421).

19 L Folliot Lalliot and C R Yukins, 'COVID-19: lessons learned in public procurement. Time for a new normal?’ (2020) 3 Concurrences $46-58<$ http://ssrn.com/abstract $=3685860>$. 
should be left unturned, on either front. However, this may not be a practical approach, or necessarily the preferable one, in particular concerning public oversight. Having already stretched public accountability institutions bogged down on the (myriad) details of COVID-related procurement and commissioning can detract from their ability to properly function post-COVID. This can be the case in the UK, for example, where the immediate future will bring the not smaller challenges of ensuring adequate governance, oversight and accountability of Brexit-related issues. In that regard, it can well be that a sort of 'amnesty' can be either formally declared or pragmatically adopted, so that regulators and other oversight bodies are not still looking at this crisis when the next one looms. Conversely, there seems to be a clear need for more (much more) academic research into the COVID-related practices and adaptations, both to draw the boundaries of any new 'light-touch regime' for (no longer unregulated) extremely urgent procurement and, perhaps more importantly, to reflect on how to maximise the opportunities brought forward by digitalisation from a governance perspective.

\subsection{THIS IS NOT THE FINAL CRISIS - WHAT PROCUREMENT RULES FOR AN UGLY 'NEW NORMAL'}

The other thing that worries me, and much more, is that the pandemic is likely just a taster of the systemic distortions to come in our lifetime (not to mention the lifetime of our children and grandchildren). Given the institutional and social inertia against the adoption of truly radical sustainability-orientated procurement and consumption practices, ${ }^{20}$ we can already foresee that dealing with the manifold implications of the climate emergency will at some point (rather soon) become the new (and from then on, permanent) extremely urgent need. At some point, extremely urgent will be the 'new normal' and that brings the question of what rules we need for that. From a dystopian perspective, it seems that unregulated procurement would only add corruption, maladministration and economic waste to the environmental meltdown - perhaps even accelerating the mutually reinforcing decomposition of institutional and physical ecosystems. The only way to try and strike a more positive chord (and try to avoid that ugly future) seems to be to get cracking with seriously rethinking procurement to bring sustainability (both environmental and economic/institutional) at its core, and to also get serious in harnessing the potential for digital technologies to accelerate its uptake. ${ }^{21}$ In the end, there are no hopes for a vaccine against climate change.

\section{Conclusion}

This commentary has offered some reflections on the emerging themes and early lessons that can be learned from the procurement and commissioning response to the COVID19 pandemic. These point clearly towards the need for more academic work on understanding the specific details of this response, as well as a broader reconsideration of the adequate regulation of extremely urgent procurement. It could well be that not many regulatory reforms are required and that the main improvements to be had depend on the proper harnessing of the potential that digital technologies offer. This area of exploration is particularly crucial in the face of the bigger challenges posed by climate change. It deserves our attention and effort.

20 For a call to action, see e.g. S Schooner and M Speidel, "Warming Up" to sustainable procurement' (2020) 60(10) Contract Management 32-41 <http://ssrn.com/abstract=369742>.

21 For some exploratory thoughts, see A Sanchez-Graells, 'Digital technologies, public procurement and sustainability: some exploratory thoughts' (2019) SSRN working paper

$<$ http://ssrn.com/abstract=3482341>. 